\title{
CONTRA A SOCIOLOGIA PÚBLICA: será ela a melhor forma de tornar a Sociologia relevante?'
}

\author{
Jonathan H. Turner*
}

\begin{abstract}
A bem difundida recepção do chamamento por uma sociologia pública confirma o desejo quase desesperado da disciplina tornar-se pertinente às grandes questões atuais. Em várias partes do mundo sociólogos sentem-se, de alguma forma, marginalizados na esfera pública, e raramente são indagados acerca das suas percepções. Assim, a sociologia pública parece propor um caminho para que as várias sociologias se unam, visando a torná-la mais relevante a diferentes públicos e comunidades. O presente trabalho, entretanto, argumenta que esse convite para uma sociologia pública é, na realidade, por uma sociologia radical de esquerda, que vai infundir ideologia e pregação moral à face pública da sociologia. O resultado é que a disciplina tende a afastar mais do que engajar os próprios públicos que tenta influenciar. Mais sensato seria manter a ênfase na ciência e na neutralidade de valor, desenvolvendo uma mentalidade de "engenharia", na qual os sociólogos utilizam suas teorias e pesquisas para ajudar os clientes a solucionar problemas do mundo real. Somente após o legado da prática bem sucedida da sociologia científica, a sociologia será considerada de interesse para as questões mais importantes do debate público.

PALAVRAS-CHAVE: sociologia radical, ciência, engenharia, prática, teoria sociológica.
\end{abstract}

Ochamamento de Michael Burawoy (2004a, 2004b, 2004c, 2005a, 2005b) por uma "sociologia pública" certamente ecoou entre os sociólogos, não só nos Estados Unidos, mas efetivamente em todo o campo da sociologia. Sua defesa estimulou a continuidade da discussão sobre o papel da sociologia, e seu argumento de que as "quatro sociologias" conseguem, de alguma forma, corrigir os extremos ou os "pontos cegos" uma das outras parece, à primeira vista, um toque de gênio, ao integrar o que normalmente se constituem facções hostis na disciplina. Em primeiro lugar, situa-se a sociologia profissional, comprometida com a ciência e que enfatiza a revisão pelos pares da atividade científica, buscando acumular conhecimento sobre o mundo empírico (eu poderia acrescentar: explicar como o mundo social opera com as teorias gerais). Em segundo, vem a sociologia para políticas

\footnotetext{
* Doutor em Sociologia pela Universidade de Cornell. Professor do Departamento de Sociologia da Universidade da Califórnia.

Department of Sociology. University of California, Riverside. Riverside, CA 92521-0419. jonathan.turner@ucr.edu

${ }^{1}$ Traduzido por Maria Lavínia Sobreira de Magalhães. Revisão Anete Ivo aceita pelos organizadores do dossiê.
}

públicas, que ao oferecer "soluções" a seus problemas especiais utiliza o conhecimento sociológico para atender às necessidades de clientes e financiadores ou patrocinadores. Em terceiro lugar, vem a sociologia crítica, que questiona as suposições e os pontos de vista morais fundamentados nas premissas de base de toda a sociologia, mas especialmente hostil à sociologia científica. $\mathrm{E}$, por último, vem a sociologia pública, que engaja os públicos - tanto o geral quanto os vários públicos locais - em questões contemporâneas e problemas que consideram importantes.

Segundo Burawoy, cada um desses quatro tipos de sociologia possui seu lado sombrio. $\mathrm{Na}$ sociologia profissional, existe uma tendência autorreferencial em relação às questões nem sempre muito importantes; na sociologia para políticas públicas, observa-se uma submissão em relação às demandas dos clientes; na sociologia crítica ao dogmatismo e na sociologia pública, ao seu caráter transitório. Há certo grau de verdade em relação a essas afirmativas, e a maioria dos sociólogos reconhece essas patologias. Assim, a crença de Burawoy de que as quatro sociologias juntas 
podem corrigir, ou até mesmo curar as patologias umas das outras é uma ideia que agrada, embora de difícil execução prática. Na realidade, conforme já argumentei em outro trabalho (Turner, 2005), existem perigos reais em perseguir peremptoriamente a presença pública da sociologia, pela simples razão de termos quatro sociologias distintas que não podem facilmente ser harmonizadas.

$\mathrm{O}$ argumento de Burawoy deixa claro que a sociologia pública deve ser o veículo pelo qual a sociologia crítica e radical tornar-se-ia dominante. Se os sociólogos expõem suas políticas aos públicos, em muitas sociedades estes possivelmente prestarão ainda menos atenção aos sociólogos do que o fazem atualmente, principalmente em sistemas capitalistas, como o dos Estados Unidos. Em um mundo cheio de problemas de organização dos seres humanos, solidarizo-me com uma sociologia levada a sério. Porém ainda não estou convencido de que uma sociologia impregnada de ideologia consiga fortalecer-nos e, mais importante, conceder-nos um lugar à mesa do poder, onde estão sendo tomadas as mais importantes decisões, que afetam o bem-estar das pessoas.

É realmente gratificante ver os sociólogos serem consultados e até mesmo constatar sua presença como "especialistas” na mídia. Porém eles correm o risco de se tornarem simplesmente mais um grupo de "cabeças falantes" na televisão. Se realmente a ciência conseguisse disciplinar esse discurso, eu poderia então ter esperanças. Entretanto, levando em conta que, no mínimo, metade da disciplina está comprometida com uma ideologia em especial - com tendências de esquerda - o que, a propósito, compartilho com os colegas sociólogos -, vejo poucas possibilidades da sociologia pública ser disciplinada. Os públicos mais amplos não precisam “ouvir nosso ‘discurso”, como muitos dos meus colegas já fazem em suas salas de aula para atrair alunos, ou como constato em tantas apresentações em reuniões "profissionais". Muito do que se apresenta como sociologia constitui-se, essencialmente, num caminho ideologicamente percorrido sobre o que é bom para as pessoas e para a sociedade, na grande maioria total- mente fora do controle da explicação científica, de como o mundo social realmente funciona. Na realidade, muitas vezes a ciência é vista como o "inimigo" de uma sociologia ideologicamente orientada. Se os sociólogos ficarem expostos dessa maneira a públicos cada vez mais amplos, quase sempre mais conservadores do que eles, vamos nos distanciar deles, perdendo, assim, aquilo que aspiramos a exercer: a influência.

Na realidade, é constrangedor, para não dizer humilhante, que uma disciplina dedicada à compreensão do mundo social seja ignorada não só pelo público, mas por todos em geral. Também é duplamente enervante que uma disciplina com um modelo equivocado de comportamento humano e com muito pouca compreensão sobre as forças sociais mais amplas do universo social - ou seja, a economia - tenha tanta influência. Nos Estados Unidos, até os historiadores recebem mais destaque na esfera pública dos que os sociólogos. E, infelizmente, o mesmo se aplica a alguns psicólogos. Assim, entendo as frustrações dos sociólogos quanto ao fato de outros profissionais, muito menos qualificados, estejam sendo consultados para discutir a maioria das questões públicas e não eles. Essa frustração constitui-se o cerne do interesse global predominante na proposta de Burawoy, o de reconciliar as quatro sociologias sob a bandeira da sociologia pública, embora o objetivo real seja subordinar todas as sociologias à sociologia crítica. Porém, para que a sociologia exerça influência duradoura nas políticas públicas e nas decisões tomadas pelos que detêm o poder, precisamos engajar públicos como cientistas, com explicações que sejam úteis. Engajar plateias como “cruzadas morais" tende a reduzir ainda mais a influência já bastante limitada que os sociólogos exercem em debates e decisões importantes.

Ao invés de partir para as cruzadas públicas, a sociologia precisa resolver algumas divisões fundamentais referentes à sua prática - divisões que a sociologia pública não consegue e que, na realidade, não tem interesse em resolver. Uma delas é a divisão, há longo tempo, entre os que desejam ser neutros em relação a valores e os que que- 
rem defendê-los, ou a divisão entre ciência versus moral (ética). Outra separação é a retórica de anticiência da maior parte da sociologia contemporânea, seja da sociologia crítica ou a crença filosófica na impossibilidade de uma ciência natural do processo social. Outra, conforme observa Burawoy, é a divisão entre a sociologia para políticas públicas, ou o que chamarei de sociologia aplicada ou prática sociológica, e todas as outras sociologias. Outra divisão é a separação drástica entre a teoria e a pesquisa, como também entre a teoria e a prática. Muito da sociologia profissional é autorreferencial, como Burawoy apropriadamente ressalta, ou simplesmente enfadonha, uma vez que é excessivamente descritiva, frequentemente estatística, sem outra justificativa a não ser a de ser estatística. Ademais, muito raramente a sociologia empírica testa as teorias. Por outro lado, muito do que é chamado de teoria, na sociologia, não é científico, mas uma combinação de sociologia crítica, história das ideias, veneração dos heróis, dos mestres antigos no cânone sociológico, praticamente um filosofar derivativo e um pessimismo epistemológico sobre as possibilidades de a sociologia ser uma ciência explicativa.

Assim, a sociologia possui uma imensa casa que precisa ser organizada antes de engajarmos o público com o que temos. E o que temos mesmo? Conhecimento acumulado? Percepções teóricas comprovadas? Indignação moral? Não ficou claro para mim que a sociologia tenha tudo isso a oferecer ao público no estado atual. Gostaria de abordar cada uma dessas questões, começando pelas consequências de assumirmos uma perspectiva moral.

\section{SOCIÓLOGOS PÚBLICOS COMO ‘CRUZADOS MORAIS'}

O âmago da missão de Burawoy é tornar a sociologia uma disciplina moral - talvez um pouco disciplinada pela sociologia profissional. Porém, Burawoy deseja finalmente, que o engajamento da sociologia seja moral e que desafie suposições éticas, fundamentos, debates e deci- sões. Em vários pontos ele menciona alguns estudos admiráveis da sociologia nos Estados Unidos para embasar seu ponto de vista de que a melhor análise sociológica traz também implicações morais. Por exemplo, o Relatório Coleman (sobre escolas segregadas), o Relatório Moynihan (sobre a desintegração da família africana), o livro de Vaughn (sobre o desastre do Challenge) e o trabalho de Massey e de vários coautores sobre a imigração e segregação na América. Todos foram bastante elogiados, e gostaria de juntar-me a Burawoy nessa avaliação.

Esses trabalhos influenciaram decisivamente a organização política e as decisões nos Estados Unidos, e figuram entre os poucos que o conseguiram. O que todos esses relatórios oferecem são dados quantitativos e uma análise embasada. Eles também possuem uma mensagem moral, porém limitada, o que não chega a ser um "sermão". Os dados falam por si. Não há razão para adotarmos excessivamente uma perspectiva moral, mas a minha impressão é a de que Burawoy gostaria de algo mais: transformá-los em um caso moral, envolvendo o público e aqueles que decidem politicamente em um debate moral. Assim, creio, esses excelentes relatórios tornar-se-iam uma desculpa para emitir a moral dos sociólogos. Nas sociedades, como, por exemplo, a dos Estados Unidos, esse tipo de cruzada moral não levará a sociologia muito longe. Além disso, é bem provável que a cruzada moral acabe reduzindo a credibilidade dos dados, suficientes para sustentar uma causa, fazendo com que esta seja menos plausível - exatamente a última coisa que a sociologia pública almejaria.

Não seremos sociólogos muito competentes - públicos, científicos, aplicados, ou até mesmo críticos - se tudo que tivermos a oferecer ao mundo for nossa indignação, revestida na roupagem de extremistas no espectro político. Douglas Massey $(1993,2005)$ corretamente conclamou por uma "política fraca", na qual os pesquisadores políticos (e eu acrescentaria os teóricos) recuariam e ficam subordinados à coleta, análise e explicação teórica dos dados. Existe uma "força na política fraca”, pois os dados e a análise minuciosa estão 
em primeiro plano, e não a ideologia política ou moral que, inicialmente, se constituiram na motivação para a realização da pesquisa. Precisamos mostrar ao mundo externo o poder da sociologia como ciência, mais do que desfilar nossas convicções morais. Creio que a defesa de Burawoy tende a subordinar nossa ciência à pregação moral, o que simplesmente afastaria e indisporia as pessoas que queremos influenciar.

Burawoy enfatiza que a sociologia pública e aplicada precisa ser disciplinada pela sociologia profissional (científica). Porém, se partimos da visão de que devemos adotar uma perspectiva moral, é improvável que as outras sociologias consigam disciplinar a sociologia pública. A minha experiência é a de que, sem um firme propósito de manter os próprios critérios pessoais e morais longe da ciência, a moral e a ideologia sempre vão prevalecer sobre a análise. O resultado final é que nos tornaremos 'cruzados morais' e nada mais.

A sociologia dos Estados Unidos, assim como aconteceu em muitas sociologias nacionais, surgiu com uma personalidade dividida. No caso estadunidense, grande parte do discurso voltavase para produzir uma sociologia "científica", porém somente um dos primeiros sociólogos americanos - Lester Ward - foi preparado como cientista; os demais possuíam formação jornalística e outras não-científicas. Portanto, o compromisso com a ciência era mais verbal do que real. A sociologia estadunidense nunca solucionou essa divisão: a moral versus a ciência; a defesa de valores versus a neutralidade científica. Os que tentam permanecer neutros em relação aos valores são vistos comumente como "parte do problema" (conforme definido pelos sociólogos críticos), ou como "os que se vendem" às forças do "mal" na sociedade. Ao passo que aqueles que se tornam excessivamente ideológicos devem tolerar esse tipo de rejeição que agora lanço à proposta de Burawoy.

Desde sua fundação a sociologia nos Estados Unidos teve muitas oportunidades para comprovar sua utilidade (ver, em relação à análise crítica, Turner e Turner, 1990), porém, ou a disciplina não conseguiu impressionar, pois realizava pes- quisas destituídas de rigor e sem base teórica, ou se tornou uma cruzada moral. Portanto, não é de estranhar que os benfeitores abastados (sejam eles pessoas ou fundações) se desinteressem da disciplina, e acho que não será surpresa se nossos poucos patrocinadores e clientes restantes venham a nos abandonar novamente, se a proposta de Burawoy continuar a ganhar adeptos.

Deixem-me apresentar outro exemplo de como os sociólogos não conseguem exercer a sociologia pública de modo a fazer a diferença. No começo da invasão dos Estados Unidos ao Iraque, a maioria dos sociólogos, nos Estados Unidos, estava contra a guerra. Os membros da Associação Americana de Sociólogos (ASA) apresentaram uma petição e um manifesto contra a guerra, e, como era de se esperar, a aprovação foi grande. Acho que este foi um esforço ineficaz, pois ninguém no poder, ou o público em geral, prestou realmente atenção ao que os sociólogos pensavam. E, considerando que o público apoiava a invasão, poucos ouviriam os sociólogos e, mesmo se o fizessem, só iríamos conseguir irritá-los - o que não seria exatamente um bom começo para a sociologia pública.

O que argumentei na época e que defendo agora é que, se os sociólogos quisessem engajar o público em relação à guerra, era preciso que fôssemos acadêmicos e não cruzados morais. São muitos os sociólogos que estudam guerras, impérios, forças armadas, dinâmicas do sistema internacional e outros aspectos da dinâmica em jogo no Iraque. São esses os indivíduos que deveríamos apresentar ao público como especialistas, com capacidade para conversar sobre a invasão e seus efeitos possíveis, de forma neutra. Tenho certeza que até Burawoy concordaria com esse ponto, porém sua sociologia pública deseja ir mais adiante e proclamar como imoral (uma ponderação com a qual compartilho, mas que não é pertinente, vinda de um sociólogo público competente) esse esforço pela política americana. No começo da guerra, precisávamos de pessoas frias e analíticas frente ao público, estudiosos com dados históricos, com discernimento sobre a dinâmica da operação militar e suas múltiplas consequências não planejadas 
e imprevistas. Não se conseguiu encontrar esses cientistas em lugar algum. Em vez deles, usamos o clã costumeiro de enfeite, políticos ignorantes, com alguns generais reformados fazendo os comentários. Onde estavam os sociólogos? Não se conseguiu encontrá-los na esfera pública, porque não somos respeitados o bastante para que se percebesse que detemos um conhecimento apropriado a acrescentar aos comentários sobre a guerra. $\mathrm{O}$ fato de sermos cruzados morais também não teria ajudado, e assim ninguém prestou atenção ao manifesto da Associação Americana de Sociologia ou aos sociólogos adeptos de uma perspectiva moral. Porém, por que foi assim? Por que se considerou que os não-sociólogos tinham mais conhecimento e qualificação do que os sociólogos sobre a guerra e a formação do império? As respostas a essas perguntas podem ser encontradas nas demais divisões da disciplina.

\section{A PREVALÊNCIADARETÓRICADA ANTICIÊNCIA NA SOCIOLOGIA}

A sociologia científica está sendo atacada de vários ângulos, quando Burawoy (2005b) proclama "o fim da ciência pura". Segundo muitos sociólogos críticos, os esforços para que permaneçamos neutros em relação aos valores contraria os princípios morais. De acordo com sociólogos mais voltados para a filosofia, a sociologia científica ao imitar a epistemologia das ciências naturais está fadada a falhas, pois os seres humanos e suas criações - a sociedade e a cultura - supõem o poder de interferência e a capacidade de modificar a natureza fundamental da realidade social. O resultado é que não existem leis sociológicas atemporais e duradouras. Consequentemente, para estes sociólogos críticos a sociologia científica não é possível. É bem verdade que podemos coletar dados e usar a estatística, mas a ciência não é um método, e nem um amontoado de dados: é um meio de explicar através de teorias como o universo social opera.

Se a sociologia não consegue ser uma disciplina científica, seria impossível disciplinar o dogmatismo da sociologia pública radical? Acho que a sociologia, ao estabelecer conjuntos de princípios teóricos, consegue ser apropriada aos problemas e às questões atuais, os quais, avaliados empiricamente, são trazidos à esfera pública. A maioria dos sociólogos críticos tem uma perspectiva anticiência, com algumas exceções notáveis (incluindo talvez Burawoy, embora eu não tenha certeza pela leitura de seus trabalhos mais importantes). Eles veem a ciência como inerentemente conservadora-especialmente a ciência social que tenta ser uma ciência natural - e, de certo modo, rejeitam os esforços de desenvolvimento de leis sociológicas capazes de explicar fenômenos significativos de interesse para o público e para os formuladores de políticas.

Atualmente, é grande o ceticismo em relação ao desenvolvimento da sociologia explicativa. Porém, na realidade, a sociologia teórica tem muito a explicar sobre o universo social. Infelizmente, nosso conhecimento não está totalmente codificado, e, sem um compromisso de desenvolver e integrar teorias sobre processos sociais gerais, a sociologia não consegue concretizar seu potencial de informar os públicos. Uma sociologia pública que não seja dominada pela ciência e pelo conhecimento dos sociólogos é uma sociologia que passa para o modo crítico, dominado espontaneamente por ideólogos. No que são nitidamente momentos enganosos. Burawoy diz tudo o que é correto sobre a sociologia profissional, embora ele pareça pensar que ela tem mais a ver com a coleta de dados do que com a explicação teórica. E assim, os que respondem ao seu chamamento por uma sociologia pública, estão mais propensos a serem os teóricos nesse campo, e não cientistas. Entretanto, a chave para uma sociologia pública viável está nos cientistas, pois o mundo precisa de uma explicação sobre o porquê dos acontecimentos. Se o público não aprecia o rumo que estes tomaram, é a sociologia teórica e não a de caráter ideológica que tem mais possibilidades de oferecer uma orientação para mudar o rumo dos acontecimentos, se é que seja possível modificá-los.

A teoria disciplina a ideologia, indicando o 
que é possível ou não. A ideologia simplesmente reafirma o que seria realmente possível, mas certamente não é o caso. O público precisa é da explicação sociológica dos acontecimentos e períodos, não de nossas divagações morais. Existe um vasto corpo de ciência social explanatória, em especial, da sociologia explanatória, à disposição dos clientes, dos formadores de políticas e dos públicos. Os problemas com os quais as sociedades humanas se deparam são demasiadamente importantes para permitir que a melhor faceta da sociologia para o mundo exterior seja um punhado de teóricos, muitas vezes condescendentes e quase sempre irritantes. Eles não ajudam a alcançar esses objetivos através das doutrinas de suas ideologias, pois vão se tornar um outro ator ainda mais político no fluxo e refluxo da política. Naturalmente, se as pessoas desejam ser políticas e agir moralmente enquanto cidadãs, quem pode se opor? Porém, nos seus papéis de sociólogos, como cruzados morais, eles só atingem nossa disciplina. Um modo de operação "brando" ou "apolítico" é o melhor, se a sociologia quiser exercer um impacto real no mundo, fora dos confins de nossas seguras carreiras na academia.

\section{A DESCONEXÃO ENTRE TEORIA, PESQUISA E PRÁTICA SOCIOLÓGICAS}

Não obstante o considerável avanço da teoria explicativa nos últimos quarenta anos, a sociologia profissional ainda apresenta grandes lacunas entre teoria, pesquisa e prática. Assim, antes que a sociologia profissional seja usada como um corretivo para qualquer coisa, ela precisa primeiro arrumar a própria casa. São evidentes as lacunas entre as várias linhas. Em primeiro lugar, muito do que se chama de "teoria", em sociologia, não é teoria científica, como mencionei antes. A história das ideias, a crítica dos males existentes, a filosofia, o negativismo epistemológico e muitas outras atividades são chamadas de “teoria”, muito embora não expliquem nada e, na realidade, frequentemente sintam prazer em dizer que a sociologia não consegue explicar nada cientificamente. Existem, na ver- dade, muitos programas de pesquisa teórica que representam um grande avanço acerca do que era conhecido em relação ao universo social há apenas meio século. Ainda assim, a ala teórica da sociologia profissional divide-se entre as científicas e anticientíficas.

O resultado é que os pesquisadores não testam as teorias sistematicamente; na realidade, a maioria dos testes de teoria é feita pelos que formulam as teorias. Nas ciências maduras, existe uma divisão de trabalho entre a teoria e a pesquisa, uma vez que são atividades intelectuais bem diferentes. A teoria é abstrata, afastando-se dos casos empíricos para explicar fenômenos genéricos, enquanto que a pesquisa segue na direção dos casos empíricos para medir os acontecimentos de forma precisa. Quando é preciso que os teóricos sejam também pesquisadores, suas teorias tendem a ser limitadas e preenchidas pelo alcance das escalas, enquanto que os pesquisadores simplesmente, na falta de teorias científicas para testar, coletam os dados e descrevem acontecimentos. Assim, existe uma grande lacuna entre a teoria e a pesquisa. E vai ser difícil para a sociologia ter muito que dizer em relação a questões importantes, a não ser que seus teóricos desenvolvam teorias e seus pesquisadores as testem, de modo que a disciplina consiga acumular mais conhecimento. Sem conhecimento, o que vamos dizer aos nossos "públicos"?

A prática sociológica também tende a não ter uma base teórica. Como Burawoy salienta, quase sempre, em alguns contextos aplicados, as necessidades de agradar aos clientes tornam a explicação dos acontecimentos menos importante. Entretanto, se a prática fosse voltada para a teoria, os que estão comprometidos com o trabalho sociológico aplicado poderiam usar essas teorias para propor soluções aos problemas dos clientes. Visto que a prática envolve intuição, extrapolação e coleta de dados descritivos, ela não consegue contribuir significativamente para a disciplina da forma como deveria. A utilização das teorias para os problemas do mundo real é somente uma forma de avaliar as teorias, quando se transpõe o conhecimento sociológico da academia para o mundo real. De fato, como saliento 
brevemente, a ala da sociologia baseada na prática teoricamente orientada - na verdade, a ala de engenharia - é uma forma bem melhor de tornar o conhecimento sociológico pertinente e útil para os clientes e públicos. Porém, a sociologia terá de fazer por merecer, oferecendo conhecimento útil cliente por cliente, durante períodos mais longos de tempo do que o apelo para uma sociologia pública poderia permitir. Se a sociologia for útil, sua reputação será valorizada e lentamente ela vai tornar-se mais apropriada aos públicos e formuladores de políticas - não porque os engaja, mas sim porque ela detém um conhecimento relevante.

\section{OS PERIGOS DA SOCIOLOGIA CRÍTICA: por uma sociologia mais pública}

Levando-se em conta as muitas divisões na sociologia além das que foram destacadas por Burawoy, duvido que uma sociologia pública orientada pela sociologia crítica possa ser disciplinada. A agenda não tão oculta assim da sociologia pública de Burawoy é a institucionalização adicional da ala crítica da disciplina. Burawoy observa, é claro, que a sociologia crítica pode ser dogmática, porém ele privilegia nitidamente essa forma de sociologia. Ele cita alguns estudiosos que escreveram pistas decisivas, enfatizando questões como, por exemplo, "de que lado estamos?", "sociologia para que?” e "sociologia para quem?” Além disso, é crítico em relação à sociologia para políticas públicas ou à prática sociológica. Segundo ele mesmo, também "é crítico em relação a Jonathan Turner (1998, 2001, 2008), Irving Louis Horowitz (1993), Andrew Abbot (2001), e Stephen Cole (2001) que censuram a infiltração das políticas e das ideologias dos movimentos sociais na sociologia”. Portanto, não há dúvidas de que o plano de Burawoy é ter uma sociologia pública moral e politicamente motivada, que engaje os públicos com as ideologias de esquerda. Ele vai mais longe, ao apoiar alguns referenciais, como, por exemplo, o esforço não-sucedido de Talcott Parsons de construir um método teórico unificado, enquanto pro- clama em voz alta o nome de um grupo de anciãos descontentes da sociologia de um passado distante, como, por exemplo, C. Wright Mills, Alvin Gouldner e Alfred McClung Lee. Ele está convocando os sociólogos a fazer um julgamento moral sobre o que é e como deve ser uma "boa sociedade". Esse é um dogmatismo intelectual na pior das suas facetas e, no caso de realizar-se, certamente vai afastar muitos públicos. Felizmente, essa marca da sociologia será ignorada, até mesmo ridicularizada, pois, para a grande maioria do público que ela tenta influenciar, parece muito piegas e moralista.

Devido ao seu dogmatismo, a sociologia crítica não possui um histórico muito bom de acúmulo de conhecimento. Na realidade, quando os conceitos têm caráter moral de forma autoconsciente, quase sempre são extremados e não-sujeitos a compromissos ou rejeição, se os dados não apoiam conclusões ideológicas. Vamos analisar as posturas críticas dos fundadores da sociologia, como, por exemplo, as previsões de Marx sobre revolução e alienação, a análise de Durkheim sobre a anomia e egoísmo, a preocupação de Weber sobre a gaiola de ferro (na verdade deveria ser uma cerca de aço). Será que esses diagnósticos foram precisos? Não tenho certeza; todos eles foram exagerados. Mais recentemente, temos a multidão solitária de Riesman, a busca de Nisbet por comunidade, a elite de poder de Mill, a ação comunicativa ideal de Habermas e a colonização do mundo da vida. Para onde essas ideias levaram a disciplina? Na realidade, será que são empiricamente corretas? Nunca poderemos saber, pois semelhantes à fé e à religião, elas não são testadas e, se o fossem, a evidência negativa seria rejeitada. Assim, a perspectiva moral de direita ou de esquerda ainda é moralismo e não ajuda realmente a resolver os grandes problemas com os quais se deparam os seres humanos e seus padrões de organização social. A perspectiva moral faz declarações curtas e sonoras na mídia, mas raramente oferece um diagnóstico fundamentado dos problemas e sugestões teoricamente informadas (em oposição às ideológicas) para corrigir as situações problemáticas.

As declarações curtas e de ordem moral 
podem prender a atenção do público, como ficou bastante evidente nas estações de rádio $\mathrm{AM}$ de direita nos Estados Unidos. Sua ala de esquerda está certamente mais próxima de minhas inclinações morais e políticas, mas também elas fazem mais barulho do que substância. Um verdadeiro diálogo político entre esquerda e direita também pode ser bom para democracia, como processo político em geral, pois poderia engajar a coletividade de cidadãos, mas tenho dúvidas se esse engajamento por si só possa solucionar nossos problemas. O que é necessário não é tempestade ou contra-tempestade, porém conhecimento em relação a questões e problemas particulares. Se a sociologia não fornecer esse conhecimento, então os que estão lhe procurando vão tentar encontrálo em outro lugar, como acontece atualmente, muito embora o tipo de conhecimento oferecido por economistas, historiadores, cientistas políticos e até mesmo por psicólogos não seja o mais apropriado. Porém, se a sociologia deixar cair a bola, como o fez no passado, outros vão tornar a agarrá-la e ela será mais uma vez marginalizada.

A convocação de Burawoy por uma sociologia pública é atrativa, pois se abriria a todas as possibilidades consideradas corretas para os sociólogos: uma chamada para ajudar os oprimidos, os humilhados, os que tiveram seus direitos civis cassados, os pobres, os impotentes, e outros públicos, enquanto se visualiza como o inimigo desses valorosos públicos os detentores de dinheiro e de poder. Esse tipo de polarização não consegue muito, a não ser levantar as tropas sociológicas para gritar e bramir. Segundo Burawoy, sociologia pública significa que os sociólogos devem tomar parte dos movimentos sociais - na realidade, ser a "vanguarda" desses públicos, a partir da segurança dos seus gabinetes na academia.

Sustento o ponto de vista de que, se os sociólogos desejam ajudar as pessoas, temos de ir além da chamada e da convocação às armas. O fato de sermos transformados em soldados de infantaria ou líderes de um movimento social não nos garante muito poder, e nem a capacidade de ajudar as pessoas às quais emprestamos nossa revol- ta moral. Não é preciso um doutorado, ou acúmulo de conhecimento de toda uma vida, para ser um ativista. Eu sei disso como alguém que, quando muito jovem, foi ativista do movimento pelos $\mathrm{Di}$ reitos Civis no sul dos Estados Unidos. Se a pretensão é se tornar um ativista - algo que vale a pena fazer na arena política - então que o seja. Porém, se quisermos fazer com que a sociologia seja relevante para os problemas enfrentados pelas pessoas, usemos nosso treinamento e qualificação de sociológicos. Algumas vezes, tudo de que precisamos para mudar a política é fornecer dados descritivos, como exemplifica o relatório de Coleman no caso emblemático de segregação escolar nos Estados Unidos, ou o que a equipe de Douglas Massey $(1993,2005)$ forneceu ao Congresso estadunidense em relação às questões de imigração. Os dados não mudam a mente das pessoas, mas produzem um efeito expressivo em momentos-chave nos debates públicos. Uma política "branda" é uma forma bem melhor de sociologia do que a política de jogo duro dos moralistas.

Porém, em relação às questões importantes, tenho ainda uma visão bem maior do papel dos sociólogos no debate público. A sociologia como ciência pode oferecer bem mais ao mundo do que a sociologia como uma torre de babel ou fonte principal da revolta moral. A ciência requer o desenvolvimento e o teste das teorias explicativas, acumulando, assim, conhecimento que pode ser utilizado para lidar com os problemas do mundo real. Ainda assim, para a sociologia crítica a ciência é quase sempre considerada como parte do problema, e não sua solução. Como isso seria possível?

\section{COMO A CIÊNCIA TORNOU-SE O PROBLEMA E NÃO A SOLUÇÃO?}

Burawoy descreve a carreira sociológica típica como aquela que passa por quatro estágios. Os estudantes de graduação são atraídos pela sociologia pela sua relevância aparente no mundo social. Em seguida, as escolas de pós-graduação ao forçar alimentarem-se de teoria-padrão (científica) 
e os métodos quantitativos e estatísticos privam esses alunos deste altruísmo. Esse estágio seria seguido por uma competição renhida para garantir um posto acadêmico no qual as publicações e o "não desagradar alguém" são mais importantes. Assim, é possível que, no quarto estágio, quando encontram alguma segurança profissional, os impulsos críticos reprimidos do estudioso possam "deixar de ser segredo" e manifestarem-se. Essa caracterização não é totalmente imprecisa, ao menos em relação ao primeiro estágio. O segundo estágio, no qual a tirania das ciências domina -é um tanto exagerado. O terceiro, pelo menos segundo minha experiência, também é já que observei que os sociólogos radicais não permanecem em silêncio antes de obterem seus postos (na realidade, é justamente o oposto). E assim, o último estágio também não foi alvo de uma descrição exatamente acurada. Entretanto, esta descrição revela o viés de Burawoy: a ciência (pelo menos a ciência normal) é ruim, a sociologia crítica é boa. O ativismo é bom, ao passo que a neutralidade de valor na sociologia é ruim. Minha experiência na academia, nos últimos quarenta e cinco anos como sociólogo, é a de que, se existe tirania, ela não se origina da ciência, mas sim da "correção política" - pelo menos no contexto acadêmico estadunidense.

O êxito dos movimentos sociais na sociedade mais ampla foi internalizado pela academia e continua sendo fonte constante do despertar moral, mesmo quando a sociedade já se pacificou e seguiu em frente. Normalmente é o corpo docente, mais do que os alunos, que fica "colérico" e dogmático em suas crenças de que determinados tópicos só podem ser estudados da forma "correta" e que alguns tópicos não podem ser estudados porque são "nocivos". Não há dúvidas de que determinadas categorias de pessoas e tópicos foram excluídos do cenário, durante o último século, pelos preconceitos do "homem, branco, de classe média" da academia, e foram necessários esforços para mudá-los. Na realidade, foram relativamente bem sucedidos - pelo menos do ponto de vista das ciências sociais - no campo de humanidades de faculdades ou universidades estadunidenses.
Portanto, tendo em vista minha própria experiência, a ideologia crítica está bem viva e ativa na academia e é, como Burawoy observa em relação à sua patologia, um tanto dogmática e intolerante. Assim, simplesmente substituímos um conjunto de problemas por outro. Se for nessa direção que o comprometimento moral nos leva, não acho que sua institucionalização tenha sido algo especialmente bom para a academia (foi bom para uma sociedade mais ampla, pois as oportunidades dos grupos sociais destituídos aumentaram, embora ainda haja muito mais a ser feito sobre isso). Assim, se algo foi reprimido nos departamentos de sociologia, é mais provável que tenha sido a ciência "dura" e o apelo à neutralidade de valores.

O que me perturba é que os muitos problemas enfrentados pelos públicos no mundo social precisam da sociologia científica. Não é necessário que os sociólogos digam às pessoas que elas têm problemas; elas já o sabem. Dessa forma, não necessitam de sociólogos de vanguarda para engajálas em torno de um movimento ou organização. Elas, geralmente, já têm capacidade para tanto. O que precisam é do conhecimento - imparcial e preciso - sobre o mundo social, que pode ser utilizado pelos públicos, clientes, formuladores de políticas ou quem tiver um problema de organização social. Porém, no universo de Burawoy, nosso conhecimento científico parece suspeito, pois não só é autorreferencial, seja lá o que significa, mas também não é moral. Os dados sempre devem explicitar certas conclusões politicamente aceitáveis; e as teorias que não criticam são parte do problema e não da solução. Chegamos a esse estado de coisas não pela tirania da ciência, mas sim pela tirania da sociologia crítica e de outros modelos de perfeição, virtude e retidão política da academia, pelo menos nos Estados Unidos. A sociologia pública não foi sendo retirada das pessoas à medida que iam passando pela pós-graduação e iniciavam suas vidas profissionais. Na verdade, ela lhes foi sendo incutida insistentemente, quando elas não tivessem a atitude política "correta" ou, mais possivelmente, reforçada e intensificada se elas já a tivessem. 


\section{COMO TORNAR A SOCIOLOGIA RELEVANTE}

Talvez pareça absurdo meu ponto de vista de que a sociologia pública de caráter moral possa se tornar rapidamente uma sociologia irrelevante, no mínimo fora da disciplina. Os públicos locais e os clientes que enfrentam problemas não precisam ser estimulados moralmente ou engajados por sociólogos. Eles precisam de dinheiro, de organização e poder, nada que os sociólogos estejam em condições de oferecer. Os públicos mais amplos possivelmente não serão receptivos a pronunciamentos sociológicos de natureza moral, com tendência de esquerda, pelo menos no contexto dos Estados Unidos. O que eles precisam é de dados e explicações que superem seus preconceitos e, infelizmente, sua ignorância. O mesmo é válido para os formuladores de políticas. Enquanto a ala da sociologia crítica se restringir à academia, o dano é pequeno, a não ser limitar o escopo da busca sociológica. Mas, no caso de atingir um público mais amplo, poderia desgastar a credibilidade e a capacidade da sociologia proporcionar um conhecimento útil aos que precisam. A sociologia pública ao acusar criticamente poderia danificar gravemente nossas possibilidades de atingir uma sociologia consequente - quando o mundo realmente necessita de conhecimento sobre a organização dos seres humanos.

Assim, a sociologia pública, na forma como é defendida por Burawoy, não soluciona os pontos de fratura da disciplina; somente os ressalta. Ademais, privilegia duas das quatro sociologias e rejeita as outras duas: a sociologia científica e a prática. Somos conduzidos por Burawoy na direção errada. Eu recomendaria justamente a direção oposta, privilegiando a ciência e a prática como a melhor direção para a sociologia, agora e no futuro, tornando a sociologia uma disciplina com mentalidade de Engenharia.

A simples ideia da "engenharia social" é altamente questionada nos Estados Unidos e em outras partes. Portanto, usarei esse rótulo apenas para chamar a atenção para um fato simples: as ciências maduras possuem aplicações de engenha- ria. O que, então, é a engenharia no sentido geral e a engenharia social no sentido específico? Quase sempre a engenharia relaciona-se ao emprego de princípios teóricos gerais, via métodos empíricos, para problemas práticos de construir ou de demolir algo. O engenheiro de estruturas conta com equações em livros, ou agora incorporadas em algoritmos de computador, que determinam o que é necessário para construir um tipo especial de estrutura. Os princípios teóricos, por fim, os de física, são menos importantes do que os métodos empíricos contidos no algoritmo de computador. O mesmo é verdadeiro para a sociologia. Temos um vasto conhecimento do universo social. Ele pode ser expresso em princípios teóricos abstratos, os quais, por sua vez, podem ser desdobrados em métodos empíricos para os praticantes. Não há nada no universo social que nos impeça de nos tornar engenheiros sociais, com exceção talvez do cinismo presunçoso em relação à ciência que, atualmente, é tão preponderante na sociologia crítica. Já demonstrei antes como desenvolver métodos empíricos gerais. Portanto, não entrarei aqui em detalhes (Turner, 1998, 2001, 2008).

O melhor caminho para que os sociólogos atraiam os públicos e os formuladores de políticas é como engenheiros, embora usando um outro rótulo. Dessa forma, começaremos a criar princípios gerais para os problemas dos clientes, reduzidos à expressão mais simples em métodos empíricos, como, por exemplo, clientes com problemas para manter os empregados, desânimo, alienação e muitas outras questões potenciais. O cliente também pode ser um formulador de políticas preocupado com questões mais importantes, como, por exemplo, a imigração, o emprego de tecnologias ecológicas, o controle do contágio de infecções e muitos outros problemas. Todos esses são por natureza problemas sociológicos, além dos princípios teóricos que lhes são pertinentes.

Meu ponto de vista, então, é tornar a prática sociológica mais eficiente rumo a uma mentalidade derivada da engenharia. Muito frequentemente, a intuição, os vieses ideológicos, as extrapolações e outros modos de avaliar as situa- 
ções são utilizados para aconselhar os clientes, em vez de ideias teóricas que foram se acumulando no corpus do conhecimento sociológico durante o último século. Por exemplo, se um cliente traz ao praticante da sociologia um problema relativo à forma de despertar a solidariedade, certamente a sociologia pode reforçar as condições que aumentam ou diminuem a solidariedade; o conhecimento dos detalhes da situação do cliente pode ser utilizado para despertar o estímulo à solidariedade. Usando outro exemplo, os sociólogos estão bastante familiarizados com o conflito. Portanto, se um cliente apresenta um problema que gira em torno de conflitos, certamente podemos oferecer sugestões, pois as condições que potencializam os conflitos são também variáveis que atuam para tentar reduzi-los.

Assim, a sociologia precisa treinar novamente seus praticantes para que sejam mais teóricos; e os teóricos precisam afirmar as teorias de maneira formal, para que fique claro o que a teoria postula. Então, alguns teóricos precisam começar a montar o corpus de conhecimento sobre os processos sociais, de modo que possam ser usados pelos praticantes - como um sistema de índice cruzado de princípios da prática sociológica. Não estou sugerindo que os praticantes se tornem teóricos ou viceversa, porém insisto que as teorias se expressem de forma que possam ser testadas e aplicadas ao mundo real. Infelizmente, muito da teoria em sociologia não se exprime nesses termos, e, portanto, não é muito útil na vida real. Se institucionalizarmos a teoria na prática, a sociologia vai ser mais respeitada pelo seu conhecimento. Vai levar tempo para que a utilidade da sociologia seja disseminada mais amplamente, mas, se nossas aplicações do conhecimento de engenharia forem comprovadamente úteis, a sociologia será cada vez mais valorizada, e nossa influência nas decisões políticas aumentará.

Se adotarmos a proposta de Burawoy para que a sociologia pública engaje públicos em questões morais, a disciplina pode até ter compensações no curto prazo, porém o dano será duradouro. Se formos vistos como um bando de moralistas de esquerda, não seremos valorizados pelo que conhecemos sobre o funcionamento do mundo social. Nas sociedades em que a política tende à esquerda, talvez tenhamos acesso às posições de poder, não como sociólogos, mas como serviçais ideológicos. Acho que é bem melhor seguirmos o caminho mais lento, impressionando os clientes quanto ao que podemos fazer, e, com o tempo, ganhar cada vez mais credibilidade, para exercer, no final das contas, uma influência verdadeira onde compense. É possível que Burawoy esteja propondo que façamos as duas coisas e que tenhamos a perspectiva moral disciplinada pela ciência, mas acho que isso na prática dificilmente funciona. Como disse anteriormente, a ideologia quase sempre fala mais alto que a racionalidade e a ciência.

O que é central em minha estratégia é que precisamos informar os clientes sobre o que pode ser feito (sobre seus problemas), mas, igualmente importante, devemos dizer-lhes o que não pode ser feito. Por exemplo, se uma organização possui uma hierarquia coerciva, existem limites quanto ao que é possível, digamos, em termos de aumentar a solidariedade ou de desdobrar subsolidariedades na hierarquia que trabalhem contra as metas da organização. Os idealistas (teóricos) raramente consideram as proposições de que algumas metas da ideologia podem ser atingidas. Assim, o conhecimento sobre as leis da dinâmica sociocultural também permite que sejamos realistas e ofereçamos orientação de que haja esperança de realmente mudar uma situação problemática. Trazendo um exemplo extremo aos meus objetivos, os sociólogos conhecem muito sobre as condições crescentes das desigualdades na distribuição de recursos. Algum desse conhecimento já foi codificado e mais conhecimento pode ser codificado. Consequentemente talvez ele possa ser utilizado para abordar a preocupação do cliente em relação às desigualdades. Os ideólogos simplesmente poderiam partir da premissa de que a desigualdade é um mal que deve ser eliminado, quando, na realidade, sabemos que isso não é possível em grandes sistemas complexos orientados pelo mercado e regulados pela concentração de poder. Assim, esses ideólogos estão pregando no deserto. O engenheiro pode oferecer 
um conselho mais realista sobre o que é e o que não é possível, levando em conta as particularidades empíricas da situação. O ideólogo, ainda, pode ver a situação como se o engenheiro estivesse "se vendendo" - como Burawoy certamente faz com os praticantes da sociologia caracterizados como submetidos às necessidades dos clientes. Existe uma grande diferença entre sermos dirigidos pelos clientes ou darmos conselhos realistas, em termos práticos, à luz dos limites concretos da situação.

Será que os engenheiros sociais simplesmente se venderiam a clientes com dinheiro? Alguns poderiam fazê-lo, outros não. Ademais, se não acharmos que "clientes certos" estão tendo acesso ao conhecimento sociológico, não há nada que impeça um engenheiro social de dar conselhos, oferecidos gratuitamente. Na realidade, se os advogados e médicos gananciosos podem fazê-lo, com certeza sociólogos com maior consciência moral e menos gananciosos certamente também podem fazer a mesma coisa. É possível, portanto, "tomar partido" de quem queremos ajudar. Esses clientes não precisam de soldados de infantaria; precisam é de especialistas com conhecimento que os ajudem a atingir seus objetivos, seja lá quais forem. Assim, os engenheiros sociais podem permitir que suas políticas os ajudem a escolher àqueles a quem estejam dispostos a ajudar. Porém, com o distanciamento moral e emocional necessário para analisar as situações do ponto de vista teórico. Quais as forças que estão em jogo? Quais as leis e princípios da sociologia que são pertinentes? Qual a energia dessas forças? Quais as contra-forças existentes? E assim por diante. Questionamentos semelhantes não são questões morais. Elas levam à análise sociológica, utilizando linguagem acumulada e codificada.

\section{TRAZER A ENGENHARIA E A PRÁTICA SOCI- OLÓGICA PARA O CENTRO DA DISCIPLINA}

Com a ala da disciplina de engenharia alinhada aos clientes, essa situação poderia inspirar os teóricos a começarem a afirmar suas teorias de forma mais precisa e formalmente, de forma que possam ser utilizadas. Além disso, as aplicações de engenharia das ideias teóricas representam uma forma - tomada como sendo menos rigorosa e precisa - de testar a plausibilidade das ideias teóricas. Quando as ideias teóricas são utilizadas nas aplicações de engenharia, e quando elas funcionam (ou deixam de funcionar), então foi feito um teste da teoria. E esses testes podem ser feitos sem que seja realizada a revisão pelos conselhos de ética da disciplina nas universidades, embora, nos Estados Unidos, é bem provável que os advogados venham a revisar as sugestões do engenheiro para evitar processos. Por exemplo, um sociólogo, cujo nome não citarei, fez um estudo sobre os problemas de rotatividade de pessoal em uma organização. Ele utilizou a análise de redes sociais para examinar a natureza dos vínculos entre os funcionários e descobriu que os que deixavam a empresa normalmente tinham sido colocados à margem de outras redes geralmente mais densas. Eles tinham menos elos com os outros e, portanto, sentiam-se isolados e, assim, mais propensos a sair. Uma descoberta admirável, com muitos dados para apoiar a proposição de que a solidariedade aumenta com a densidade das redes sociais. Porém, algo aconteceu na forma de programar a solução óbvia: os advogados ficaram preocupados com os dados, pois a gerência da organização poderia ser forçada a levar os dados ao tribunal como parte do processo de "descoberta" nas cortes estadunidenses, se um funcionário decepcionado processasse seu empregador anterior. Tais dados poderiam ser então interpretados como um ambiente de trabalho "hostil", uma vez que os empregados estariam marginalizados (uma situação ilegal nos Estados Unidos). O resultado: os dados nunca foram utilizados para implantar as soluções óbvias à organização.

Assim, problemas sempre existem, especialmente em sociedades como a dos Estados Unidos, com sua superprodução de advogados, o que, consequentemente, estimula os processos na justiça. Todavia, a análise de dados coletados na organização e a utilização de ideias teóricas bem co- 
nhecidas poderiam ter solucionado ou, no mínimo, mitigado o problema; e o cliente poderia ficar satisfeito (na realidade, muito embora os dados não pudessem ser utilizados, ou a orientação informada oficialmente ser implantada, o cliente - uma grande empresa estadunidense - ficaria impressionado com que o que o sociólogo foi capaz de fazer). Se a sociologia fosse exitosa com esse tipo de esforço, seria convidada a sentar à mesa de estrategistas políticos com mais frequência e, desse modo, influenciar as decisões que podem exercer grande efeito na vida das pessoas. É esse potencial que a mentalidade de engenharia apresenta, e, embora consuma muito mais trabalho e dedicação para que seja atingida a longo prazo, é mais compensadora para a sociologia e para os sociólogos do que os ataques radicais e efêmeros na esfera pública.

Todavia, tornei-me cético quanto ao que a prática sociológica nos Estados Unidos possa se converter. Aliás, a seção de prática sociológica da Associação Americana de Sociologia foi recentemente renomeada por eles mesmos de "Prática Sociológica e Sociologia Pública”. Infelizmente, os praticantes da sociologia foram colocados à margem da disciplina, quando, na realidade, deviam estar no núcleo da sociologia científica. E, portanto, no que parece uma mudança mais drástica, para tirar partido da recepção bem difundida do convite de Burawoy para a sociologia pública, a seção da "prática" na Associação Americana de Sociologia modificou seu título, fato que interpreto como uma tática para conseguir mais membros e ficar mais importante em termos do que é considerado sociologia "quente", e a sociologia pública é "quente", se é que é algo mais que isso. Portanto, enquanto o que proponho é possível e passível de ser realizado, fico cético quanto às probabilidades de uma prática sociológica orientada teoricamente ou quanto à sociologia aplicada nos Estados Unidos. Minha esperança talvez esteja em algum outro lugar no mundo, mas, novamente, afirmo que é mais difícil e que requer consideravelmente mais disciplina do que o chamamento para uma sociologia pública.

\section{CONCLUSÃO}

A sociologia pública, agora, é um movimento social intelectual e não mostra indícios de que mudará de curso dentro da disciplina. Os sociólogos permaneceram por tanto tempo à margem dos debates públicos sobre políticas e das decisões políticas, igualmente relevantes, que, agora, vão tentar se agarrar a qualquer coisa que lhes garanta importância nos assuntos do dia. Certamente compartilho desse sentimento e relembro as dificuldades, o meu esforço despretensioso de influenciar as políticas em algumas oportunidades em que fui convidado para a mesa de tomada de decisões. Foi com grande frustração que vi os economistas ocuparem esse espaço, muito embora suas recomendações, com certeza, estivessem fadadas ao fracasso (uma vez que não conhecem as leis sociológicas). Entretanto, não existe um caminho fácil. Este deve ser alcançado, acho eu, pela ligação da teoria científica à prática. Porém, como agora ficou claro, grande parte da teoria, na sociologia, não explica nada, e muito da prática está prestes a lançar-se no trem expresso da sociologia pública, sem fazer um árduo trabalho conceitual. Seria esse trabalho - que nos confere respeito - que, com o tempo, permitir-nosia engajar públicos e políticas de forma compensadora para a sociologia e para o mundo social, que precisa, desesperadamente, de ajuda.

Assim, recomendo aos meus colegas sociólogos que evitem ser seduzidos pelo chamamento de Burawoy e de muitos outros por uma sociologia pública. É uma ideia fascinante, articulada de forma magistral e eloquente, mas o que ela oferece tem poucas possibilidades de acontecer, pois os sociólogos não são respeitados nas muitas esferas nas quais gostaríamos de exercer alguma influência. E não somos respeitados por não sermos capazes de demonstrar plenamente o que nosso conhecimento científico tem a oferecer aos clientes, públicos e formuladores de políticas. Na realidade, meus colegas "teóricos" e muito outros veem a ciência como parte do problema da sociologia, e não como a solução para sua marginalidade. Uma disciplina que rejeita a ciência, em nome do compro- 
metimento moral, tem poucas oportunidades de exercer influência onde conta, e não consegue ajudar os mesmos públicos que precisam do conhecimento sociológico. Já são muitos os pregadores na esfera pública; os sociológicos adeptos da perspectiva moral dificilmente serão vistos na torre de babel construída nesse setor. Portanto, se esse fato tornarse real, a sociologia pública não vai prejudicar (e nem ajudar) aqueles a quem queremos ajudar, mesmo que venha a prejudicar, no longo prazo, os desenvolvimentos futuros da própria sociologia.

Burawoy proclama (2005b) que a sociologia atingiu agora o "fim da ciência pura", e que seu objetivo é converter a sociologia em uma disciplina moral, que engaje os públicos. Porém, quanto aos sociólogos impulsionados ideologicamente, a ideologia vai quase sempre remover os obstáculos do pensamento alternativo, com exceção, talvez, dos que formulam contra ideologias. Burawoy pode estar certo quanto a ser esse o rumo da sociologia. $\mathrm{E}$, se esse for o caso, ela vai ficar cada vez mais irrelevante na esfera pública. Terá pouca influência fora da disciplina propriamente dita, e não será um veículo para a mudança, o que seria a perda de seu próprio objetivo. Conseguiria, quando muito, expor a sociologia ao ridículo do público. Isso seria aceitável se significasse que a sociologia poderia realizar algo, mas sua "nova onda" de sociologia fará muito pouco, a não ser fazer com que os sociólogos ideológicos se sintam bem em relação a si mesmos. Burawoy (2005b) criticou os que desafiam seu método como "excessivamente emocionais”. Porém é difícil ficar parado e ver uma disciplina envolvida no caminho autodestrutivo da irrelevância. Portanto, o normal é que aqueles que estão comprometidos com a ciência se sintam consternados, senão ofendidos. Pode não haver esperança para a sociologia estadunidense, mas espero que as sociologias, em outras partes do mundo, ainda mantenham o compromisso com a ciência pura e evitem o chamamento sedutor, porém vazio, da sociologia pública.

(Recebido para publicação em maio de 2009) (Aceito em julho de 2009)

\section{REFERÊNCIAS}

ABBOTT, Andrew. Chaos of disciplines. Chicago: University of Chicago Press, 2001.

BURAWOY, Michael. Manifesto for public sociologies. Social problems. Berkeley, University of California Press, n. 51, p. 124-130, 2004a.

Introduction. Social problems. Berkeley: University of California Press, n. 51, p. 103-106, 2004 b.

Public sociologies: contradictions, dilemmas, and possibilities. Social Forces. Chapel Hill: Southern Sociological Society/Department of Sociology. University of North Carolina. n. 82, p. 1613-1626, 2004c.

For public sociology. American Sociological Review. American Sociological Association (ASA), n.70, p. 4-28, 2005a.

Third-wave sociology and the end of pure science. The Ámerican Sociologist, n. 36, p. 151-165, $2005 \mathrm{~b}$.

COLE, Stephen. What's wrong with sociology? New Brunswick: Transaction, 2001.

HOROWITZ, Irving Louis. The decomposition of sociology. New York: Oxford University Press, 1993.

MASSEY, Douglas. Assessing Scientific Basis of American Sociology. Presentation at the American Sociological Association meetings, Atlanta, Georgia, USA, 2005.

; N. A. Denton. American Apartheid: segregation and the Making of the Underclass. Cambridge, MA: Harvard University Press, 1993

; DURAND, J.; MALONE, N. J. Beyond Smoke and Mirrors. Mexican immigration in an Era of economic integration. New York: Russell Sage, 2002.

TURNER, Jonathan H. Must sociological theory and practice be so far apart? Sociological Perspectives. Berkeley, University of California Press, n. 41, p. 244-58, 1998.

Social engineering: Is this really as bad as it sounds? Sociological Practice, n. 3, p. 99-120, 2001.

Is public sociology such a good idea? The American Sociologist, n. 36, p. 27-45, 2005.

The practice of scientific theorizing in sociology, and the use of scientific theory in practice. Sociologica Focus. Ohio, North Central Sociological Association (NCSA), n. 41, p. 281-300, 2008.

TURNER, Stephen Park; TURNER, J. H. The impossible science. Newbury Park, CA: Sage, 1990. 


\section{AGAINST PUBLIC SOCIOLOGY: not the best way to make Sociology relevant}

\section{Jonathan H. Turner}

The widespread reception of the call for a public sociology confirms the discipline almost desperate desire to be relevant to the big social issues of time. Sociologists in many nations have felt somewhat marginalized in the public arena, rarely being asked about their insights. Thus, public sociology appears to offer a way for the various sociologies to come together to make sociology more relevant to different publics and communities. However, it is argued in this paper that this call for public sociology is, in reality, radical-left wing sociology that will infuse ideology and moral preaching into sociology's public face. The result will be that the discipline will alienate more than engage the very publics it seeks to influence. Far more sensible is to retain an emphasis on science and value neutrality, and to develop an "engineering" mentality in which sociologists use their theory and research to help clients solve real world problems. Only after a legacy of successful practice using scientific sociology will sociology be considered relevant to the bigger issues of public debate.

KEYWORDS: radical sociology, science, engineering, practice, theory.

\section{CONTRE LA SOCIOLOGIE PUBLIQUE: serait- elle la seule manière de rendre la Sociologie importante?}

\section{Jonathan H. Turner}

Le très grand accueil réservé à l'appel à une sociologie publique confirme le désir pratiquement désespéré de voir cette discipline devenir pertinente face aux grandes questions actuelles. Dans plusieurs parties du monde de nombreux sociologues se sentent, d'une certaine manière, marginalisés au sein de la sphère publique puisqu'on ne s'enquiert que très rarement de leurs perceptions. C'est ainsi que la sociologie publique semble proposer une alternative pour que les diverses sociologies s'unissent afin que la sociologie devienne plus intéressante pour des publics différents et des communautés diverses. Cependant, le travail que nous présentons montre que cet appel à une sociologie publique est, en réalité, un appel à une sociologie radicale de gauche qui va inculquer l'idéologie et le discours moral au caractère public de la sociologie. Il en résulte que cette discipline a tendance à éloigner plutôt qu'à engager les publics qu'elle essaie d'influencer. Il est bien plus sage de continuer à mettre l'accent sur la science et sur la neutralité de valeur en développant une mentalité d' "ingénierie" au sein de laquelle les sociologues utilisent leurs théories et leurs recherches pour aider les intéressés à trouver une solution aux problèmes du monde réel. Ce n'est qu'après avoir légué une pratique efficace de la sociologie scientifique que la sociologie sera considérée valable pour les questions plus importantes du débat public.

Mots-CLÉs: sociologie radicale, science, ingénierie, pratique, théorie sociologique.

Jonathan H. Turner - É um "Distinguished Professor" de Sociologia da University of Califórnia, Riverside, Doutor em Sociologia pela Cornell University (1968). Entre 1999 e 2004 foi editor de Sociological Theory, periódico publicado pela American Sociological Association. É reconhecido especialista em teoria social, e suas áreas de interesse de pesquisa são: a sociologia das emoções, relações étnicas, instituições sociais, estratificação social e a bio-sociologia. Foi professor visitante em várias Universidades: Cambridge University; Universitat Bremen e Universitat Bielefeld; Shandong University e Nan Kai University. É autor de inúmeros livros, dentre os quais destacam-se: The Structure of Sociological Theory (Wadsworth, 1998) e com Anthony Giddens Social Theory Today, 1987, publicado no Brasil pela UNESP, em 1996. 